\title{
Documento curricular da escola bragantina e gestão escolar democrática: um olhar a partir dos princípios educativos freireanos
}

Curriculum document of the bragantina school and democratic school management: a view from the freirean educational principles Documento curricular de la escuela bragantina y la gestión escolar democrática: una mirada desde los principios educativos freireanos

ROGERIO ANDRADE MACIEL http://orcid.org/0000-0003-1673-5215

Universidade Federal do Pará

Núcleo Interdisciplinar de Pesquisa em História da Educação e Currículo na Amazônia Faculdade de

Educação

Bragança, PA, Brasil

JOANA D'ARC DE VASCONCELOS NEVES

http://orcid.org/0000-0002-3110-3649

Universidade Federal do Pará

Programa de Pós-Graduação Linguagens e Saberes da Amazônia

Faculdade de Educação

Bragança, PA, Brasi

MARCOS RENAN FREITAS DE OLIVEIRA

http://orcid.org/0000-0002-0540-9345

Universidade do Estado do Pará

Programa de Pós-graduação em Educação

Faculdade de Educação Física

Belém, PA, Brasil

\begin{abstract}
Resumo: Este estudo analisa a concepção de gestão escolar democrática Freireana no documento curricular da escola bragantina. Problematiza na antinomia entre o processo de normatização e regulação da escola pública pela lógica dos documentos curriculares contemporâneos e possíveis resistências das redes de ensino. Metodologicamente foram utilizados dois documentos para a coleta e análise dos dados. Conclui-se que o documento curricular da escola bragantina está para além de qualquer documento normativo e homogeneizador e, por ter como primazia os princípios educativos freireanos, concebe uma gestão escolar democrática, dialógica, libertadora e crítica.
\end{abstract}

Palavras-chave: Gestão Escolar Democrática. Escola Bragantina. Princípios Educativos Freireanos. 


\begin{abstract}
This study analyzes the concept of democratic Freirean school management in the curriculum document of the bragantina school. It problematizes the antinomy between the process of standardization and regulation of the public school by the logic of contemporary curricular documents and possible resistance from the education networks. Methodologically, two documents were used for data collection and analysis. It concludes that the curriculum document of the bragantina school is beyond any normative and homogenizing document and because it has Freire's educational principles as its primacy, it conceives a democratic, dialogical, liberating and critical school management.
\end{abstract}

Keywords: Democratic School Management. bragantina school. Freirean Educational Principles.

Resumen: Este estudio analiza el concepto de gestión escolar democrática freireana en el documento curricular de la escuela Bragantine. Problematiza la antinomia entre el proceso de normatización y regulación de la escuela pública por la lógica de los documentos curriculares contemporáneos y las posibles resistencias de las redes educativas. Metodológicamente, se utilizaron dos documentos para la recolección y análisis de datos. Concluye que el documento curricular de la escuela bragantina está más allá de cualquier documento normativo y bomogeneizador y, por tener como primacía los principios educativos de Freire, concibe una gestión escolar democrática, dialógica, liberadora y crítica.

Palabras clave: Gestión Escolar Democrática. Escuela Bragantina. Principios educativos freireanos.

\title{
INTRODUÇÃO
}

Este texto apresenta uma análise a respeito da experiência da gestão construída pela rede pública de ensino municipal de Bragança, Estado do Pará, um Município de 408 anos, na Amazônia paraense. Nossas inquietações originaram-se nas atividades de articulação de ensino, pesquisa e extensão entre os professores da referida rede e pesquisadores da Universidade Federal do Pará (UFPA) membros da Cátedra Paulo Freire da Amazônia em diálogos sobre a organização curricular das escolas, pautado nos sujeitos, seus contextos/territórios e as práticas pedagógicas dos docentes sob a orientação freireana, em contraposição à perspectiva homogeneizadora da Base Nacional Comum Curricular (BNCC), instituída por meio da Resolução CNE/CP n 2 2, de 22 de dezembro de 2017.

Discutir a gestão democrática na Educação Básica a partir da epistemologia freireana é compreender que o modelo democrático, antes de ser uma forma política, configura-se como uma forma de vida, caracterizada pela transitivação da consciência, resultado de trocas recíprocas, intersubjetivas, em um movimento de "sair-de si" em direção a si mesmo, ao outro e ao mundo (FREIRE, 2007). No caso deste estudo, um movimento em que o sistema público de ensino municipal gesta desde o processo de organização do currículo a partir 
das questões problemas/emergentes das escolas em suas dimensões educativas, articulando-as aos sujeitos, territórios, saberes e práticas pedagógicas, inclusive diante de um contexto de BNCC.

Efetuar a subversão sobre o aprisionamento das competências ehabilidades do Ensino Fundamental e dos direitos de aprendizagem/desenvolvimento e campos de experiências para Educação Infantil, prescrito na BNCC, tem sido um movimento coletivo, pautado por princípios educativos que possibilitam o processo de gestão escolar democrática Freireana: os sujeitos, as territorialidades e as práticas pedagógicas emancipatórias. Assim, na antinomia entre o processo de normatização e regulação da escola pública pela BNCC e possíveis resistências das redes de ensino que este artigo objetiva analisar a concepção de gestão escolar democrática Freireana nos documentos orientadores da escola bragantina.

Metodologicamente, este estudo utilizou dois documentos para coleta e análise dos dados: as Diretrizes Político-Pedagógicas e Curricular da Rede Pública Municipal de Educação de Bragança - Pará (SEMED, 2020a) e o Relatório Técnico do Departamento Pedagógico da Secretaria Municipal de Educação de Braganca - Pará, dos anos de 2017 a 2020 (SEMED, 2020b). Do primeiro, captamos os princípios educativos, quais sejam: as identidades dos sujeitos e dos territórios que constituem Bragança: da praia, da colônia, dos campos e da sede. Além das práticas pedagógicas que foram construídas numa perspectiva freireana e as orientações para a elaboração do projeto político-pedagógico da escola bragantina. Do segundo, extraímos a tessitura história da política curricular do município de Bragança até a consolidação do documento curricular da Escola Bragantina, bem como, as vozes/os registros das escolas sobre o processo de implementação dessa política.

Dessa forma, os resultados deste estudo foram articulados no sentido de apresentar na primeira seção, o processo dialógico de construção do documento curricular da Escola Bragantina; na segunda seção, os princípios freireanos que alicerçam a escola bragantina (primazia dos sujeitos, das territorialidades e das práticas); a processos constitutivos do $\mathrm{PPP}^{1}$, ancorados na perspectiva freireana, considerando os relatos registrados pelos gestores escolares; e por fim, expomos as considerações finais.

Os leitores irão identificar na sessão que trata sobre as práticas pedagógicas freireanas, três práticas que estão presentes no documento curricular: o Projeto Político Pedagógico, o Plano de Gestão e o Plano de ensino. Contudo, optamos, para este estudo, apresentar aos leitores a construção coletiva e a orientação, presente no documento a respeito da prática pedagógica no planejamento na elaboração pelo PPP, mobilizado pela gestão escolar democrática numa perspectiva Freireana. 


\section{O PROCESSO DIALÓGICO DE CONSTRUÇÃO DO DOCUMENTO CURRICULAR DA ESCOLA BRAGANTINA}

A diretriz curricular e orientadora do Município de Bragança foi construída em meio a diversos diálogos, produções de relatórios, questionários e escutas dos profissionais da educação, a fim de atender as reais necessidades de cada contexto. De acordo com o documento, o processo de construção não foi uma tarefa fácil, visto que requereu o reconhecimento do outro/com o outro, um movimento que respeitasse as produções de conhecimento construídas em cada escola, como princípio organizador do currículo, inclusive a participação da equipe técnica da Secretaria Municipal de Educação, como descreve o documento curricular da escola bragantina ${ }^{2}$ :

Assim, isso foi fundamental para materializar esse 'olhar' sobre o documento curricular da escola bragantina, constituída por sujeitos, territorialidades e suas respectivas práticas pedagógicas, sendo que estes permitiram tecer o documento curricular. (SEMED, 2020a, p. 5).

Esse documento nasce de contextos históricos, políticos e sociais, pautados na intencionalidade de orientar uma gestão democrática Freireana com os professores na Educação Básica. De 2013 a 2016, a Secretaria Municipal de Educação de Bragança fomentou e implementou um trabalho a partir de uma matriz curricular via Complexo Temático, cujo propósito foi consolidar o programa escolar Escola Bragantina em Construcão Coletiva. Este teve, como base, o Sistema de Complexos Temáticos, discutido por Moisey Pistrak (2008), educador do período pós-revolução russa, como o modo adequado para os jovens estudarem e compreenderem as relações entre os objetos e fenômenos da realidade em sua dinâmica dialética e de acordo com a teoria marxista.

No ano de 2017, a partir de um realinhamento interno, a Secretária Municipal de Educação (SEMED) reordenou suas ações e adotou oficialmente a perspectiva de um currículo Freireano de educação ${ }^{3}$. Com isso, iniciou um processo de formação partindo, primeiramente, de fomentações e experimentações mais teóricas sobre a concepção Libertadora de Educação (SEMED, 2020b).

\footnotetext{
2 A expressão documento curricular da Escola Bragantina será utilizada como sinônimo de Diretrizes Político-Pedagógicas e Curriculares da Rede Pública Municipal de Educação de Bragança-Pa.

3 Com os estudos e as formações permanentes com base na educação escolar Freireana, a perspectiva do currículo por sistema de complexos temáticos de Pistrak (2008) foi substituído em sua totalidade, devido ao atendimento de que apenas as obras Freireanas davam o suporte necessário para ações educativas da rede pública municipal de educação.
} 
Ressaltamos que essas experiências de trabalhos coletivos e currículos críticos, anteriores à Base Nacional Comum Curricular (BRASIL, 2017), ao serem marcadas pelas adversidades e também pelos limites que são inerentes à construção de uma gestão de educação pública, potencializaram a luta e a resistência em defesa de uma gestão crítica, libertadora, dialógica e emancipatória.

O movimento de formação de todos os seus atores educacionais, constituiu-se no próprio processo de legitimação da organização curricular via Teias do Conhecimento, norte teórico-metodológico da escola bragantina:

[...] a caminhada consistiu na intensificação da formação continuada dos seus educadores para a consolidação da Concepção Libertadora de Educação como tendência a ser discutida e vivenciada por toda a rede de ensino. (SEMED, 2020a, p. 8).

Em 2019, pressionada pelo parágrafo único do art. 15 que define o tempo de alinhamento dos currículos escolares à BNCC até o início do ano de 2020 (BRASIL, 2017), a Secretaria organiza-se por meio das paradas de mobilização para estudos sobre a BNCC, entretanto, os encaminhamentos dos momentos formativos reafirmam a opção do currículo pautado dos princípios educativos freireanos.

Assim, nos anos de 2019 e 2020, o processo de formação de educadores foi marcado pelo princípio educativo do diálogo entre os profissionais da rede pública municipal. Nessa direção, pautada na visão dialógica freireana (FREIRE,1987), a construção da reorientação curricular que foi mediada pela formação dos educadores de maneira horizontal, coletiva, contrapondo a formação linear, ordenada, hierarquizada, estabelecida pelos padrões da sociedade capitalista e individualista.

Desse modo, a concepção de formação de educadores na Escola Bragantina, por formações permanente, visava constituir e ser constituidora de uma gestão democrática, organizada a partir de Formação, Seminários de Gestão da Escola e Diálogo com a equipe técnica da SEMED e parada de mobilizações dos professores, conforme campo imagético a seguir: 


\section{Imagem 1 - Organização da Formação permanente de professores}

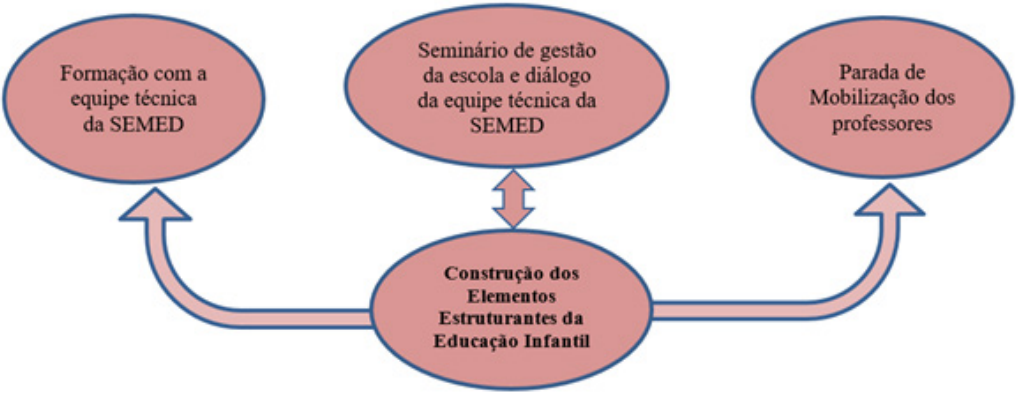

Fonte: (SEMED, 2020a, p. 604).

$\mathrm{Na}$ dinâmica permanente da formação de educadores, o início ocorre com a formação promovida a equipe técnica da SEMED. São momentos em que os técnicos consultam os relatórios das escolas, visualizam os planos de ações, o Projeto Político-Pedagógico e efetuam reunião com gestores, coordenadores e professores com a finalidade de escuta dos sujeitos do processo. Tais operações possibilitam as reflexões e as ações para o desdobramento dos planejamentos que são construídos nas formações dos educadores.

Nos Seminário de gestão da escola, ocorre outro momento de escuta e levantamentodequestões problemas com temáticas relevantes para serem discutidas nas escolas. Nesse momento, os gestores e os coordenadores vão registrando as falas significativas e os planos que serão desenvolvidos pelos professores para o planejamento escolar. São momentos de orientação, problematização e acompanhamento dos técnicos com os gestores e coordenadores, tanto nas escolas, quanto na SEMED, que constituiu-se no diálogo ${ }^{4}$ da equipe técnica da SEMED com gestores e coordenadores.

As paradas de mobilizações são momentos essenciais da formação permanente (no chão da escola), momento em que os gestores escolares irão escutar o coletivo de educadores, discutir, debater sobre as reais questõesproblemas existentes no cotidiano das escolas, o ponto de partida para o planejamento dos professores. Com a retomada da pesquisa, diálogos e discussão entre os gestores, coordenadores e seus professores, iniciam-se a construção dos Elementos Estruturantes das Escolas: o projeto político-pedagógico, no plano de gestão escolar e coordenação pedagógica e nos planos de ensino.

4 Nessa perspectiva, o diálogo é definido como “[...] encontro dos homens, mediatizados pelo mundo, para pronunciá-lo, não se esgotando, portanto na relação eu-tu” (FREIRE, 1987, p.50-51); por meio do diálogo, os humanos constroem sua significação no mundo como sujeitos não adaptados, críticos de sua existência, tornam-se humanos com o mundo e, como tal, são capazes de refletir sobre a realidade em que estão inseridos. 
Dessa maneira, a formação da equipe técnica da SEMED, o Seminário de Gestão Escolar e as paradas de mobilização constituem o processo de formação permanente do coletivo de educadores, que permitiram construir o documento curricular da escola bragantina e trazer à tona a primazia dos princípios educativos freireanos.

\section{A ESCOLA BRAGANTINA E A PRIMAZIA DOS SUJEITOS, DAS TERRITORIALIDADES E DAS PRÁTICAS}

O município de Bragança fica localizado na região nordeste do Pará, a 210 quilômetros de Belém, capital do Estado. É uma das cidades mais antigas do Estado do Pará e possui uma riqueza de cultura, saberes culturais, memórias e uma heterogeneidade de atividades produtivas, com a pesca e a agricultura familiar. Essa realidade sociocultural é importante para identificar os sujeitos e suas territorialidades como orientadores das práticas educativas dos professores na escola bragantina.

Para articular o processo de gestão democrática Freireana que possibilita a construção do documento curricular do município de Bragança, têm-se como ponto de partida a defesa pela filosofia dos sujeitos, seus contextos/ territorialidades e as práticas. A seguir visualizado no organograma do Documento Curricular da Escola Bragantina:

\section{Imagem 2 - Princípios orientadores da diretriz curricular municipal}

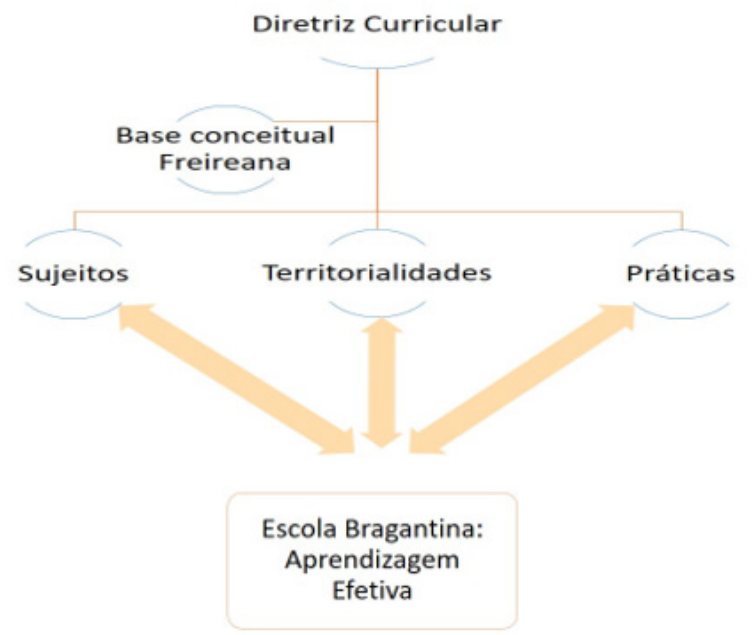

Fonte: DCB, 2020, p. 6. 
A teia supracitada foi elaborada pelo coletivo de educadores e equipe técnica da SEMED a partir de diálogos, estudos dirigidos, formações permanentes, ancoradas na Concepção Libertadora de Educação, tendo como base o refinamento teórico-metodológico-epistemológico das obras e do legado de Paulo Freire, fomentando o programa escola bragantina: aprendizagem afetiva.

Desse modo, os três princípios estão alicerçados no refinamento teórico de Paulo Freire: A filosofia dos sujeitos; seus contextos/territorialidades e as práticas são as primazias importantes para se pensar a escola bragantina e só foram possíveis de serem articulados ao documento curricular devido ao processo de formação permanente.

\section{A GESTÃO ESCOLAR DEMOCRÁTICA FREIREANA ALICERÇADA AO PRINCÍPIO EDUCATIVO DO SUJEITO DA ESCOLA BRAGANTINA}

No processo de formação permanente dos educadores é reconhecida a filosofia dos sujeitos, como construtores de uma rede de saberes: popular, da experiência; e científico que envolve uma polissemia de identidades. Sobre esse aspecto, Freire $(1995$; 2006) ressalta que esses diferentes tipos de saberes não hierarquizados são a expressão de um processo educativo, problematizador, conscientizador e libertador, de identidades:

\section{Imagem 3 - O princípio educativo dos sujeitos na escola bragantina}

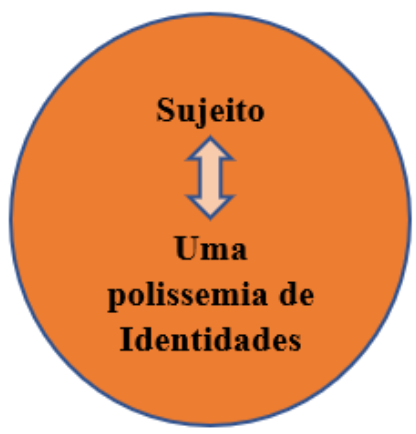

Fonte: Elaborado pelos autores. 
É nas formações permanente que ocorrem os processos de gestão democrática escolar Freireana, em cada escola (SEMED, 2020b). Cada gestão escolar discute o princípio educativo do sujeito que é defendido na escola bragantina e o articula com a pesquisa ${ }^{5}$ que os professores operam na escola, nas salas de aulas e nas comunidades.

A pesquisa possibilita interpretar as diferentes dimensões dos sujeitos em sua existência humana: suas identidades, universo vocabular, condições de vida social; suas relações culturais, ou seja, é uma forma de entender o sujeito em seu cotidiano. Isso permite aos gestores escolares, com seu coletivo de educadores, indagar: quem são os sujeitos de Bragança? Sujeito Amazônico! Sujeito Amazônida! Sujeito Bragantino! Sujeito Comunitário! Uma polissemia de identidades sobre os sujeitos que devem ser levadas em consideração para/ com o contexto escolar, de forma que, como diz Freire (1986), o sujeito deve ser entendido em suas diferenças. Sujeito em comunidade, coletivo, aberto ao diálogo, aquele que tem cultura, família, tradição, saberes, memórias, sujeito histórico e de consciência de si para trabalhar criticamente a sua situação - limite em situação de opressão.

O sujeito de identidades, no construto teórico de Freire (1987), é cognoscente. Isso, a partir de reflexões dialéticas sobre a construção do sujeito, as condições necessárias do ato de aprender e sobre a formação da consciência do indivíduo sobre si e sobre o mundo. Nessa direção, o sujeito polissêmico freireano passa constantemente por processos intersubjetivos nos quais toma consciência da própria condição de existência por meio de relações dialógicas com os iguais e com os diferentes, construindo significações como ser social. Por isso, o sujeito:

[...] sabe que é exatamente o tu que o constitui. Sabe também que, constituído por um tu - um não eu -, esse tu que o constitui se constitui, por sua vez como eu, ao ter no seu eu um tu. Desta forma, o eu e o tu passas a ser, na dialética dessas reações constitutivas, dois tu que se fazem dois eu. (FREIRE,1987, p. 103).

Desse modo, na dialética das reações constitutivas, o sujeito polissêmico é também um sujeito cognoscente: um ser de relação, capaz de construir significações sobre si, sobre sua realidade e sobre o mundo; Um ser inacabado, que busca sua completude a partir da sua ontológica vocação de humanizarse na perspectiva do ser mais; Que só se constitui com e no diálogo com o

\footnotetext{
5 Aqui existe um movimento da pesquisa sócio antropológica e as questões problemas que estão situadas no cotidiano das comunidades, cuja superação é desnaturalizar aquilo que é senso comum no universo escolar e no entorno da escola, envolve, conforme Gouvêa (1996), a apreensão da realidade, análise, organização, e sistematização, originando programas de ensino a partir do diálogo.
} 
outro, problematizando sua existência e sua realidade; Um ser responsável pela construção de sua própria história e, por ela, é impulsionado a transcender continuamente as relações de opressões (FREIRE, 1987).

Seguindo essa linha de raciocínio, a Semed (2020b), em sua filosofia dos sujeitos, contrapõe-se à (in)visilidade e à homogeneização do currículo, presentes nos documentos oficiais orientadores e normativos da BNCC, uma vez que existe uma heterogeneidade nas formas de vida articuladas ao bem viver bragantino e isso é um elemento primordial numa gestão escolar democrática Freireana que reconhece o sujeito de existência, de vida, de identidades para o saber/fazer docente nos seus múltiplos territórios sociais.

\section{A GESTÃO ESCOLAR DEMOCRÁTICA FREIREANA ALICERÇADA AO PRINCÍPIO EDUCATIVO DAS TERRITORIALIDADES DA ESCOLA BRAGANTINA}

Outro princípio educativo no processo de formação permanente de professores e presente no documento curricular que orienta os gestores escolares são os territórios. Tal como Freire (1986) anuncia que o contexto local, seus territórios e cultura são pontos de partida para identificar as contradições de um sistema opressor e excludente. O documento da Semed (2020b) defende que as territorialidades e as identidades, presentes nas 135 escolas de Bragança, estão imersas por peculiaridades de seus territórios (sede, campo, colônia e praia) e que precisam ser consideradas como orientadores de práticas docentes em cada território, onde a escola está inserida. A imagem a seguir demonstra a constituição do território do município de Bragança, Estado do Pará:

\section{Imagem 4 - Territórios que compõem o Município de Bragança}

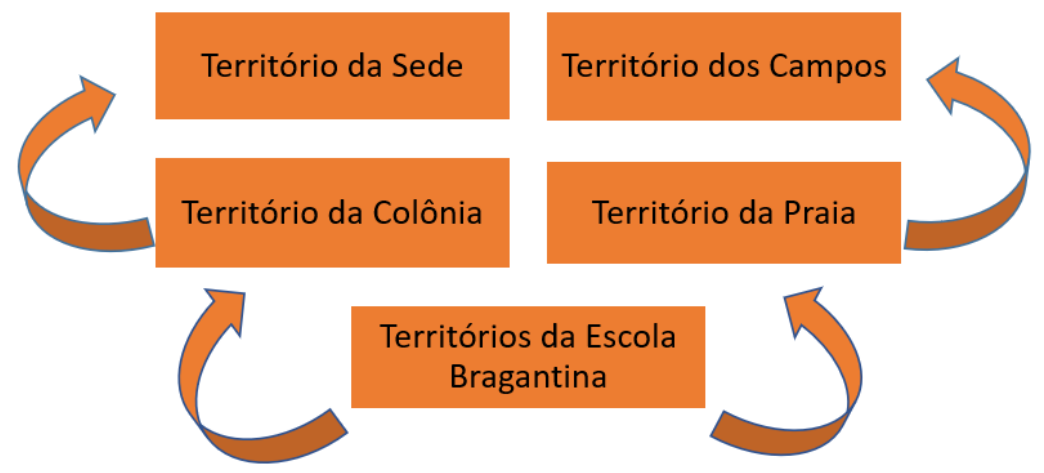

Fonte: Elaborado pelos autores, 2021 
No processo articulador entre sujeitos e territórios, o relatório da Semed (2020b) destaca a necessidade de refletir sobre os sentidos e os significados dos sujeitos da comunidade escolar, atribuindo ao seu contexto o questionamento sobre o que os diferenciam enquanto sujeitos e práticas dos demais territórios bragantinos. "É nessa articulação de sujeitos e territórios/territorialidades que teremos a dimensão da realidade local" (SEMED, 2020b, p. 53).

A rede pública municipal de educação de Bragança - Pará teve 17.997 alunos regularmente matriculares em 2020, situados na cidade e no campo, e oferta as etapas da Educação Infantil e do Ensino Fundamental - anos iniciais e finais, bem como as modalidades da educação de jovens e adultos, da educação especial inclusiva e da educação escolar quilombola. A escolas municipais são organizadas por polos geográficos e administrativos, que aglutinam um conjunto de unidades de ensino, sendo eles: Bragança, Cacoal, Treme, Montenegro, Ajuruteua, Parada Bom Jesus, Campo de Cima, Campo de Baixo. (SEMED, 2020b).

Nessa organização que compõe as escolas municipais, o currículo freireano é articulado às diferentes territorialidades. Conforme pode ser visualizado na caracterização dos polos em que as unidades de ensino estão presentes:

O Polo Ajuruteua foi assim chamado por conter as escolas nos territórios situados na região de praia ou próximas a estrada que dá acesso à praia com o mesmo nome. A região tem como fonte principal de subsistência das famílias a pesca e a coleta de caranguejo. Atividade que geralmente é realizada individualmente ou em parcerias com moradores vizinhos e familiares, seja em relações de prestação de serviço e/ou para consumo próprio[...]. (SEMED, 2020b, p.54).

[...] O polo Treme também é uma região onde a agricultura e a pesca são importantes meios de trabalho, porém a catação ${ }^{6}$ da massa do caranguejo é a atividade que mais se destaca. (SEMED, 2020b, p.54).

As escolas que ficam localizadas em territórios situados na região de praia, constituem o polo Ajuruteua; nesse território, constituídos por diversas comunidades, existe um conjunto de saberes da pesca, pescadores que acompanham seus pais, tios, avós desde pequenos e consequentemente vão passando tudo que aprenderam para as futuras gerações. Esses conhecimentos são transmitidos informalmente, oralmente, como tradição. Muitas vezes, conseguem descrever com detalhes os ciclos hidrológicos e meteorológicos que incidem em sua região, assim como outros aspectos da topografia submarina e do comportamento das espécies que ali habitam; conhecimentos esses necessários

6 O termo "catação": A "catação" corresponde ao beneficiamento para a extração da carne, popularmente chamada de "massa".

948 - Rev. Bras. Polít. Adm. Educ. - v. 37, n. 2, p. 938 - 960, mai./ago. 2021 
para a prática do trabalho e sobrevivência. E é nesse contexto rico de experiência e conhecimento que os sujeitos dos territórios "praianos" vivem. Já no Polo Treme existe o beneficiamento do caranguejo-uçá que é domiciliar e tem pouca infraestrutura, no entanto, há na comunidade do Treme uma cooperativa.

Já os polos, situados nos territórios da Colônia e Campos, são caracterizados da seguinte forma:

Os polos Cacoal e Montenegro são conhecidos como as regiões das colônias, importantes polos de produção de farinha. As regiões têm inúmeros igarapés, mas na região do Cacoal o fluxo de água tende a baixar no verão amazônico. Já o Montenegro, é o polo formado pelas comunidades criadas ao longo da PA 112 - rodovia Dom Eliseu. (SEMED, 2020b, p.54-55).

A região dos campos de cima e de baixo é caracterizada pelas inundações 'sofridas' em determinados períodos do ano, principalmente no inverno, proporcionando um cenário paradisíaco. As escolas situadas na Parada Bom Jesus o lugar tem muitas propriedades que cultivam o Feijão Caupi, tem criação de aves e algumas são presenteadas com nascentes. (SEMED, 2020b, p.55).

Nos polos Cacoal e Montenegro, a agricultura familiar é o principal meio de renda e trabalho para os moradores e o abastecedor fundamental do comércio bragantino e cidades vizinhas. Já no Montenegro, nas comunidades da região da Colônia, os rios e os igarapés pouco baixam, permitindo aos sujeitos, suas famílias e visitantes uma opção de lazer e de apoio para as atividades do trabalho doméstico e da lavoura.

$\mathrm{Na}$ região dos campos de cima e de baixo, as comunidades dessas regiões vivem da agricultura e quando na cheia, da pesca. Em alguns lugares é possível encontrar a criação de búfalos usados no trabalho do campo; em outros, como atrativo turístico. De outro modo, na Parada Bom Jesus, apesar de ser um lugar de produção, a comunidade é bastante dependente do comércio na sede de Bragança.

Observamos, então, que os polos geográficos e administrativos estão interligados às territorialidades dos sujeitos e de suas práticas culturais da agricultura, da pesca, do comércio, com o território da sede de Bragança. Dessa forma os gestores têm autonomia, considerando os diálogos sobre os princípios educativos dos sujeitos e das territorialidades, de construírem em seu planejamento escolar em cada comunidade, a exemplo, a elaboração dos Projetos Político-Pedagógicos (PPP), durante os processos de formação permanente na escola bragantina. 


\section{AS PRÁTICAS PEDAGÓGICAS FREIREANAS ORIENTADORAS DA GESTÃO DEMOCRÁTICA NA ESCOLA BRAGANTINA}

Os leitores devem estar se questionando o porquê de discutir o sujeito e os territórios e por conseguinte as respectivas práticas pedagógicas? No documento curricular da escola bragantina existe uma orientação para as escolas públicas de que os gestores escolares têm autonomia de desenvolver práticas libertadoras, a partir da análise dialética de seus sujeitos e de seus respectivos territórios.

Uma vez efetuado o levantamento dos sujeitos e das territorialidades, a comunidade escolar pode materializá-lo na forma do seguintes documentos, quais sejam: no Projeto Político-Pedagógico, na forma de Plano de Gestão Escolar; e Coordenação e Pedagógica, no Plano de Ensino Docente e/ou em outras formas de sistematização, em que coletivo de educadores tem autonomia de gerenciar o seu planejamento escolar, visto que o intuito não é o de engessar as práticas pedagógicas docentes e sim reinventá-las, conforme orienta a perspectiva Freireana. Para isso, são constituídas três formas de gestão escolar que implica (rá) na efetivação do programa escolar. São elas, apresentados no organograma a seguir:

\section{Imagem 5 - Formas de gestão escolar que implica na efetivação do programa escolar escola bragantina para /com as escolas}

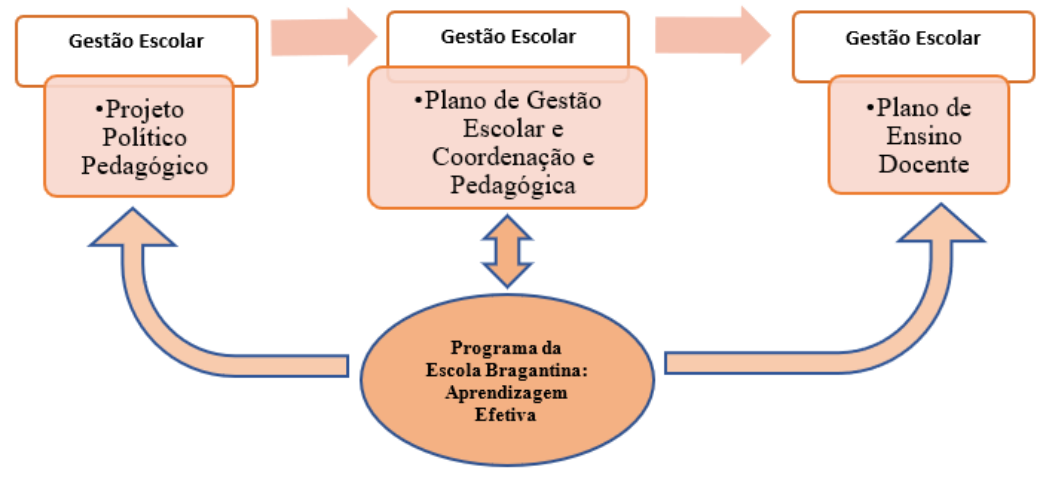

Fonte: Semed (2020a).

O plano de gestão escolar, articulado ao da coordenação pedagógica, é estabelecido pelo diálogo com o PPP e, ao ser desenhado de forma de dois em dois anos, anual, ou de quatro em quatro anos, considera as situações presentes no plano e na diversidade dos sujeitos educadores e educandos que estão atuando naquele ano letivo, logo, ele 'sofre' inúmeras revitalizações. 
Já os Planos de Ensino são oriundos da pesquisa dentro e fora da sala de aula; eles também são subsídios centrais, tanto para a construção do PPP, quanto dos planos de gestão escolares, pois parte-se do cotidiano dos sujeitos educandos, educadores, comunidade escolar que orientam as práticas nas mais diferentes formas de gestão escolar no chão da escola bragantina.

Assim, reconhecemos e identificamos, no documento curricular, a articulação entre o Projeto Político-Pedagógico, o Plano de Gestão Escolar e Coordenação e Pedagógica e o Plano de Ensino Docente. No entanto, para este estudo, apresentam-se os processos constitutivos no PPP, ancorados numa prática de gestão escolar freireana, a partir dos princípios orientadores dos sujeitos e territórios do município de Bragança.

As práticas presentes na escola bragantina:

São oriundas das práticas culturais, exercidas pelos sujeitos em suas territorialidades e nas escolas e nos faz questionar: quem são os sujeitos da escola bragantina? que práticas sociais os sujeitos desenvolvem em seus territórios? Que práticas pedagógicas e educativas existem nas escolas de Bragança? Essas práticas estão vinculadas aos saberes que os professores desenvolvem em suas práticas quando estabelecem, em seus planejamentos escolares, os saberes oriundos dos sujeitos em seus territórios, bem como, os saberes da experiência docente no cotidiano escolar, seja pela prática pedagógica quando o professor desenvolve suas práticas em sala de aula com os alunos e/ou seja na prática educativa quando o professor desenvolve práticas para além da sala de aula, nas comunidades, na escola como um todo. (SEMED, 2020a, p.7).

Nessa direção, como descreve Freire (1996), as práticas educativas que considerem suas territorialidades devem ser orientadoras de inúmeros princípios educativos: práticas da pesquisa in loco, diálogos entre os sujeitos, as práticas culturais, considerando a importância dos saberes culturais, as identidades dos sujeitos e seus territórios. São esses princípios que são destacados no documento curricular do município de Bragança. Portanto, quando se trata das práticas, elas estão associadas às duas primeiras dimensões: sujeitos e territórios, estes que possuem suas especificidades em cada lugar, contextos, que permitem o planejamento da gestão escolar, dentre eles, o PPP, com o desafio de construir a dialética cultural, ou seja, de construir uma articulação entre os sujeitos, os territórios e o próprio conhecimento escolar.

Ressaltamos que esse desafio, marcado na visão de Freire e Faundez (1985, p. 46), da necessidade de superação da pedagogia da resposta, na qual o educador "já traz a resposta sem lhe terem perguntado nada" envolto na ideia de que o ato de conhecer é uma "mera transferência do conhecimento existente" é superado pela práxis libertadora, que traz consigo a exigência de construção de novos caminhos e a desconstrução de outros que já se encontram enraizados, ou 
seja, é suplantado por práticas pedagógicas descolonizadoras que requerem essa retomada da compreensão do ser humano, como sujeito cognoscente frente ao objeto ou fenômeno a ser conhecido; sujeito que questiona, indaga, pergunta a si mesmo e ao outro. Sujeito movido pela curiosidade e pela busca do conhecimento. Uma condição inerente à existência humana e, como tal, pode se fazer presente na pedagogia da pergunta.

No caso da escola bragantina, esse processo tem sido pautado pela necessidade de elaboração e a revitalização do PPP e das formas de práticas pedagógicas que se articulam para trazer 'à tona' a organicidade da Escola Bragantina em seus múltiplos contextos sociais e territoriais (escolas do campo, da sede, das praias e das colônias) e consolidam a concepção de educação da rede municipal de Bragança-PA.

O PPP assume no processo de (re)construção da escola bragantina com o objetivo fomentar as ações didático-pedagógicas e administrativas, no que se refere à resolução das questões emergentes, identificadas no cotidiano das escolas. Seu marco legal está amparado pela Lei de Diretrizes e Bases da Educação Nacional (LDB) $n^{\circ}$ 9.394/96 que, em seu artigo 12, explicita que "os estabelecimentos de ensino, respeitadas as normas comuns e as do seu sistema de ensino, terão a incumbência de elaborar e executar sua proposta pedagógica". Essa citada Lei determina em artigo 13, inc. I, que: "Os docentes incumbir-se-ão de: participar da elaboração da proposta pedagógica do estabelecimento de ensino".

Nessa perspectiva, o documento da Semed (2020a) assinala para a perspectiva do trabalho colaborativo: professores, alunos, gestores, coordenadores, pais e responsáveis de alunos, servidores em geral, instituições parceiras, ou seja, trata-se antes de operacionalizar, de fato, uma gestão democrática articulada ao trabalho coletivo, sustentado pela participação entre seus sujeitos e contextos na construção dos princípios elementos centrais: o marco referencial, o filosofal e o operacional do PPP.

- Marco referencial/situacional do PPP: entre os sujeitos e territórios

Ao analisar o movimento dos sujeitos e territórios, por si só, enquanto uma prática pedagógica efetivada pelos atores sociais que fazem parte da escola bragantina, consideramos esses dois princípios enquanto elementos importantes para a elaboração do PPP, uma vez que delimita a aproximação com a realidade a ser investigada e trabalhada, à medida que os atores sociais da escola efetuam: um levantamento da contextualização histórica da comunidade e da escola, dos alunos que estão constituídos na turma, das necessidades inerentes à comunidade - situação econômica e educacional, dos objetivos educacionais, do quadro de professores de servidores e sua formação, das estatísticas iniciais e finais, em 
que se fazem presente a aprovação, a reprovação e a evasão -indicando o fluxo escolar, os indicadores de aprendizagem e os documentos referentes à planta da arquitetura escolar (SEMED, 2020b).

Nesse sentido, contextualizar a real situação da escola, possibilita projetar, planejar e consolidar a dimensão do projeto, estabelecida a partir da identidade social, cultural e física da instituição (CEDAC, 2016).

- Marco Filosofal/ doutrinal do PPP: os fundamentos teóricos, didáticos e os valores da instituição

Ao efetuar o levantamento do marco situacional/referencial das escolas, a partir dos seus sujeitos e territórios, os gestores escolares, com seu coletivo de educadores, identificam as questões-problemas e cotidianas no chão da escola. Um dos desafios identificados para discutir o sujeito e territorialidade, constituído no PPP, é com o princípio educativo Freireano sobre o ato problematizar as condições históricas e sociais dos sujeitos na busca do ser mais, conforme anuncia Freire (2000). Tem sido um exercício no programa escolar escola bragantina, durante as formações permanentes, discutir os seres humanos como seres inconclusos, sujeitos que podem superar suas situações limites, impostas pela sociedade opressora.

Essa limitação sobre o ato de problematizar foi identificada na seguinte assertiva: "Uma das dificuldades de nossa equipe é o de problematizar as questões no entorno da escola. Nossos professores ainda têm muita dificuldade de problematizar para se pensar os temas geradores no PPP. Por isso, é preciso fazer a formação no chão da escola" (SEMED, 2020b.).

Ressalta-se que em Freire (1980) o ato de problematizar é um ato de libertação, de transformação da realidade, faz parte de uma democracia construída na relação dialógica com seus semelhantes, que passa a ser interiorizada entre seus sujeitos. Nesta lógica, uma das estratégias identificadas para promover a problematização é o próprio processo formativo permanentes e o princípio educativo da pesquisa. "[...] Nós temos recebido formação da Secretaria Municipal de Educação e trabalhado com os professores das escolas. Hoje a gente tem inúmeros professores fazendo pesquisa na sala de aula e nas comunidades, depois disso, eles organizam com os alunos as atividades na sala de aula [...] (SEMED, 2020b).

A natureza da prática dos educadores tem sido constituída em processo contínuo de indagação, pela busca, pela pesquisa, pois, segundo Freire (1996) "[...] Fala-se hoje, com insistência, no professor pesquisador que é muito mais do que um profissional de ensino, aquele que insiste em ensinar pela pedagogia da resposta. Nesta direção a rede de ensino municipal tem mobilizado seus professores a irem além dos conhecimentos prescritos, exacerbados e impostos para o cotidiano de muitas escolas brasileiras. Assim, na escola bragantina o 
princípio educativo da pesquisa, no âmbito da escola, tem legitimado a autonomia das escolas e dos professores com o intuito de coibir a "pedagogia da resposta". As análises dos relatórios apontam que os princípios educativos, presentes no relatório dos gestores, não são homogêneos e lineares; observa-se que a reestruturação curricular de gestão freireana, na escola bragantina, vem ocorrendo em meio a processos de reflexão-ação-reflexão, cercada de conflitos e contradições, que perpassam tanto na formação permanente, quanto na materialização do currículo no chão da escola, constituindo-se a práxis educativa e a gestão democrática.

Neste movimento, as formações permanentes e as pesquisas mobilizam os processos de problematização do cotidiano escolar, dando materialidade aos princípios educativos, desenvolvidos pelo coletivo de atores sociais e, ao mesmo tempo, construindo e dando vida às escolas (marco situacional/referencial, que permite o próximo elemento constituidor, ou seja, que permite as seleções das temáticas que são desenvolvidas e os projetos norteadores de cada escola (SEMED, 2020a). Essas temáticas se traduzem na forma de temas geradores e nos eixos temáticos, articulando toda a organização do trabalho pedagógico, assim sujeitos dos processos estabelecem a proposta político-social da ação educativa.

Ressalta-se que o tema gerador e seus eixos temáticos são elementos de práticas pedagógicas, constituídos pela teia do conhecimento que promove as escolhas teóricas e metodológicas de cada contexto em que o PPP temático será construído. A teia traz como condição da organização do trabalho docente, a prática o trabalho coletivo entre educadores/as e educandos/as, desde o planejamento à sua concretude.

É nesse momento que a teia do conhecimento traz como repertório a missão da escola, seus valores, a definição e a visão de metas que nortearão os princípios educativos/curriculares para a formação política educativa dos sujeitos. Nessa perspectiva, é que foi observada o processo de construção das teias do conhecimento das escolas, elas se destacam, conforme Freire (1980), como um processo de investigação, da tematização e da problematização do interesse de cada contexto/realidade", inclusive das escolas bragantinas, localizadas no Nordeste Paraense. Dessa forma, apresenta-se o elemento estruturante da Teia do Conhecimento enquanto marco filosofal do PPP. 


\section{Imagem 6 - Proposição da Teia do Conhecimento ancorado para as escolas bragantinas}

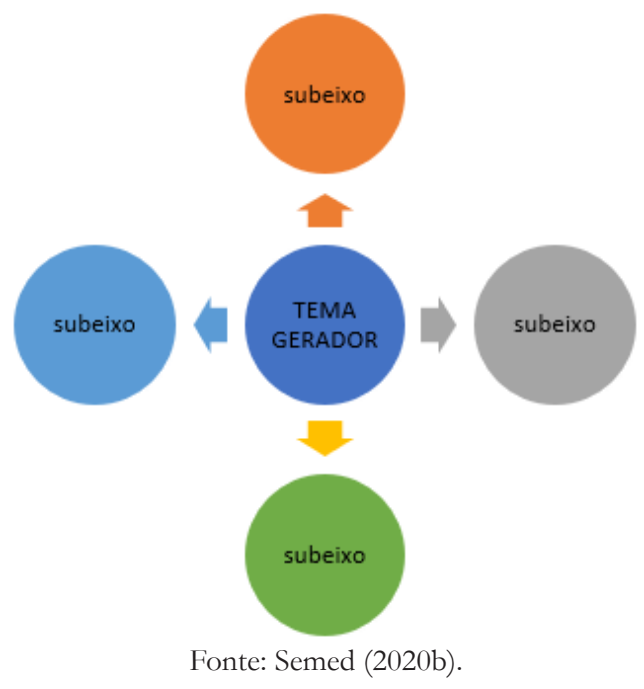

A Teia do Conhecimento, relacionando-se com as necessidades dos sujeitos, parte do princípio de que a vida cotidiana não é apenas espaço de repetição e de reprodução, é também e, sobretudo, espaço/tempo de conhecimentos válidos e necessários para o contexto escolar (Freire, 2005).

Nesse processo, observou-se ainda que as práticas pedagógicas dos gestores escolares, coordenadores pedagógicos, o coletivo de professores e a comunidade escolar constituíram-se pelo pensamento freireano, subsídiando aos marcos filosofais de seus PPP. Assim, estes são constituídos por teias de conhecimento correspondentes a real situação de existência dos educadores e educados de cada instituição. Uma heterogeneidade de práticas pedagógicas em que se observou o gestor escolar como um dos principais protagonistas dessa ação educativa.

No processo da gestão eles se questionam sobre os fundamentos freireanos: que fundamentos (freireanos) serão usados para dialogar com a nossa rede temática, (teia do conhecimento)? Que questões problemas são existentes na realidade concreta de nossa instituição? Tais questionamentos são orientadas no documento curricular em todas as etapas e modalidades de ensino da Educação Básica (SEMED, 2020b). 
- Marco operacional do PPP: entre os elementos didáticos, os saberes dos sujeitos e seus territórios

O marco operacional só tem sido possível de ser materializado, a partir dos seus dois elementos anteriores, pois, conforme o documento da Semed (2020b), os dois elementos estruturantes, o marco situacional/referencial e o marco filosofal possibilitam traçar o marco operacional do PPP nas escolas bragantinas; este que, por sua vez, baseia-se em tratar os meios, as ações e as técnicas como viabilização para a concretude do plano de ação; plano de gestão, plano de ensino, pela rede temática, dentre outras práticas.

Esse movimento de uma prática pedagógica, presente no documento da Semed (2020b), é uma premissa que permite discutir os saberes como um ato pedagógico, em que transitam diferentes etapas e modalidades de ensino, articuladas ao Conselho Escolar, e estarão presentes também na elaboração dos projetos: de educação para relações étnico-raciais; educação indígena ;de educação ambiental; de educação inclusiva; de intervenção da aprendizagem; para jovens e adultos em situação de privação de liberdade nos estabelecimentos penais; as temáticas de identidade de gênero e a orientação sexual na educação; de práticas de alfabetização e letramento; de informática educativa-inclusiva; de equipes multidisciplinares, por área de conhecimento, além de outros projetos condizentes com as diretrizes curriculares do coletivo de educadores.

Dito isto, essa prática pedagógica tem como desafio a elaboração de projetos educativos, para superar os problemas emergentes/detectados no cotidiano do contexto escolar, visto que, tais propostas operacionais têm como interesse propiciar a formação do cidadão no âmbito do sujeito, enquanto construção de conhecimento na comunidade escolar.

É fato que existem nos estados brasileiros inúmeros modelos prescritos de projetos políticos pedagógicos que são apenas reproduzidos por gestores nas secretarias municipais de educação nas escolas brasileiras. No programa escolar, Escola Bragantina Aprendizagem Efetiva, os elementos estruturantes do PPP, o marco situacional referencial, o marco filosofal e o marco operacional não se sobrepõem aos princípios educativos freireanos, pelo contrário, o PPP vai dialogando e sendo estruturado, a partir desses princípios. Uma reinvenção de prática de gestão escolar democrática que só foi possível ser realizada com inúmeros diálogos, mediados pela formação permanente, no chão da escola. Por sua vez, isso não é fácil de ser materializado com 135 escolas que têm, em seus PPP, inúmeras teias do conhecimento com o pensamento freireano sob o viés de uma gestão escolar democrática, dialogada como uma identidade dessa rede municipal de ensino. 
Nesse sentido, o marco situacional referencial, o marco filosofal e o marco operacional são orientadores de um planejamento escolar democrático que só é possível de ser realizado quando o próprio coletivo de educadores se identifica com a proposta Freireana e constrói os PPPs. São planejamentos contextualizados e imersos pelos princípios educativos freireanos sujeitos e territórios na escola bragantina, uma vez que a intenção não é homogeneizar as práticas pedagógicas de cada contexto escolar, e sim, demonstrar reflexões sobre as práticas pedagógicas que proporcionem a construção do PPP no cerne de cada escola em que é mobilizado por um dos principais protagonistas: os gestores escolares que fomentam o programa escolar: Escola Bragantina Aprendiagem Efetiva, em Bragança, Estado do Pará.

\section{CONSIDERAÇÕES FINAIS}

Ao analisar os documentos, observamos que estão intrínsecos outros princípios educativos freireanos que dialogam com os sujeitos, territórios e práticas pedagógicas dos gestores escolares.

A respeito dos sujeitos, verificamos um diálogo direto com a pesquisa na comunidade escolar e as questões problemas da realidade são princípios mobilizadores para/com a reflexão sobre os sujeitos bragantinos.

Nas territorialidades/contextos, o contexto local e a cultura são mobilizadores de entendimento da rede de saberes locais e globais em cada instituição que permitem o sujeito refletir e agir sobre as contradições históricas e excludentes da sociedade capitalista e a luta pela reinvindicação social.

Nas práticas pedagógicas, o papel do gestor escolar para a elaboração do Projeto Político Pedagógico apresenta uma matriz curricular por teias do conhecimento e seus respectivos eixos temáticos que são construídos nas escolas com os princípios freireanos, aqui supracitados.

Ficou evidente, ainda, que, no ato de construir o PPP por teias do conhecimento, se faz necessário discutir no âmbito da escola pública o ato de problematizar a realidade sociocultural dos educandos e seus educadores, pois, existem inúmeras dificuldades de efetuar esse exercício. Todavia, as formações permanentes e a pesquisa têm sido uma das estratégias construídas pelos educadores para superar essa adversidade na rede municipal de Bragança-PA.

Os processos educativos analisados no documento curricular da Escola Bragantina estão orientados por uma concepção de gestão escolar Freireana. Além disso, ele só foi possível de ser realizado, refletidos, redefinidos pelos inúmeros processos de formação permanente, construído entre a equipe técnica da SEMED com seus gestores e educadores nos Seminários de gestão da escola e nas paradas 
de mobilizações que possibilitaram os processos de construção e orientação do documento curricular da escola bragantina pelos Elementos Estruturantes das Escolas, como o PPP. Esses são mediados por outros princípios educativos freireanos, o diálogo e a escuta, que mobilizam a escola bragantina.

Pode-se concluir que a gestão democrática em Freire é gestão de conhecimento, seus produtos e processos, ultrapassando os limites da gestão pedagógica, administrativa e financeira, consagrada pela LDB n 9396/96.

Podemos inferir, ainda, que o movimento de orientação pela gestão democrática inicia-se pela formação permanente e que os dois primeiros princípios educativos, sujeitos e territórios, são a forma motriz para a construção das práticas pedagógicas de cada instituição escolar. Concluímos que o documento curricular da escola bragantina está para além de qualquer documento normativo e homogeneizador e, ao colocar como primazia dos princípios educativos freireanos, apresenta uma concepção de gestão escolar democrática, dialógica, libertadora e crítica.

\section{REFERÊNCIAS}

BRASIL. Resolução CNE/CP $\mathbf{n}^{\circ}$ 2, de 22 de dezembro de 2017. Institui e orienta a implantação da Base Nacional Comum Curricular, a ser respeitada obrigatoriamente ao longo das etapas e respectivas modalidades no âmbito da Educação Básica. Brasília, DF, Presidência da República [2017]. Disponível em: https: http://basenacionalcomum.mec.gov.br/images/historico/ RESOLUCAOCNE_CP222DEDEZEMBRODE2017.pdf. Acesso em: 16. jan. 2021.

BRASIL. Base Nacional Comum Curricular (BNCC), 2017. Disponível em: http://basenacionalcomum.mec.gov.br/images/BNCC_EI_EF_110518_ versaofinal_site.pdf. Acesso em: 28 jun. 2018.

BRASIL. Lei n $^{\circ}$ 9. 394, de 20 de dezembro de 1996. Estabelece as diretrizes e bases da educação nacional. Brasília, DF, Presidência da República [1996]. Disponível em: https://www.planalto.gov.br/ccivil_03/Leis/L9394.htm. Acesso em: 16. jan. 2021.

FREIRE, P. Pedagogia da autonomia: saberes necessários à prática educativa. São Paulo: Editora Paz e Terra, 1996. 
FREIRE, P. Pedagogia do oprimido. 30. ed. Rio de Janeiro: Paz e Terra, 1987.

FREIRE, P. Conscientização: teoria e prática da libertação - uma introdução ao pensamento de Paulo Freire. São Paulo: Moraes, 1980.

FREIRE, P. Pedagogia do Oprimido. 47. ed. Rio de Janeiro: Paz e Terra, 2005.

FREIRE, P. FAUNDEZ, A. Por uma pedagogia da pergunta. Rio de Janeiro: Paz e Terra, 1985

GOUVÊA, A. F. de. Política Educacional e Construção da Cidadania. In: SILVA, L. H. et al (org.). Novos mapas culturais, novas perspectivas educacionais. Porto Alegre: Editora Sulina, 1996. p. 35-48.

PISTRAK, M. M. Fundamentos da escola do trabalho. São Paulo: Expressão Popular, 2008.

Projeto político-pedagógico: orientações para o gestor escolar / textos Comunidade Educativa CEDAC. - São Paulo: Fundação Santillana, 2016.

SEMED. Diretrizes político-pedagógicas e curricular da rede pública municipal de educação de Bragança - Pará. Bragança: Secretaria Municipal de Educação, 2020a.

SEMED. Relatório técnico do departamento pedagógico da secretaria municipal de educação de Braganca - Pará (2017-2020). Bragança: Secretaria Municipal de Educação, 2020b.

VEIGA, I. P. A. Inovações e projeto político-pedagógico: uma relação regulatória ou emancipatória? Cad. Cedes, Campinas, v. 23, n. 61, p. 267-281, dez. 2003. 


\section{Rogerio Andrade Maciel}

Doutor em Educação pela Universidade Federal do Pará. Professor da Faculdade de Educação FACED/UFPA/Campus Universitário de Bragança. Líder do Núcleo Interdisciplinar de Pesquisa em História da Educação e Currículo na Amazônia (NIPHECA). Pesquisador do Grupo de Estudo e Pesquisa em Educação de Jovens e Adultos e Diversidade na Amazônia - (GUEAJA. E-mail: rogeriom@ufpa.br

\section{Joana D'arc de Vasconcelos Neves}

Doutora em Educação pela Universidade Federal do Pará. Atualmente é Docente do Programa de Pós-Graduação Linguagens e Saberes da Amazônia e professora Adjunta da Universidade Federal do Pará Campus de Bragança-Pa. Coordena o Grupo de Pesquisa de Educação de Jovens e Adultos e Diversidade na Amazônia. É Pesquisadora da Cátedra Paulo Freire da Amazônia. Integrante do Movimento de Educação de Jovens e adultos na Amazônia paraense. Endereço: Alameda Leandro Ribeiro - Aldeia, Bragança - PA. E-mail: jdneves@ufpa.br

\section{Marcos Renan Freitas de Oliveira}

Mestre em Educação. Professor Substituto do Curso de Educação Física da Universidade do Estado do Pará (UEPA). E-mail: marcosrenanef@yahoo.com 